\title{
In vivo imaging of beta cells with radiotracers: state of the art, prospects and recommendations for development and use
}

\author{
Olof Eriksson $^{1,2,3}$ - Maren Laughlin ${ }^{4}$ - Maarten Brom ${ }^{5} \cdot$ Pirjo Nuutila $^{2}$ • \\ Michael Roden ${ }^{6,7}$ - Albert Hwa ${ }^{8}$ - Riccardo Bonadonna ${ }^{9}$ - Martin Gotthardt ${ }^{5}$
}

Received: 8 January 2016 / Accepted: 23 March 2016 / Published online: 19 April 2016

(C) Springer-Verlag Berlin Heidelberg 2016

\begin{abstract}
Radiotracer imaging is characterised by high in vivo sensitivity, with a detection limit in the lower picomolar range. Therefore, radiotracers represent a valuable tool for imaging pancreatic beta cells. High demands are made of radiotracers for in vivo imaging of beta cells. Beta cells represent only a small fraction of the volume of the pancreas (usually 1-3\%) and are scattered in the tiny islets of Langerhans throughout the organ. In order to be able to measure a beta cell-specific signal, one has to rely on highly specific tracer molecules because current in vivo imaging technologies do not allow the resolution of single islets in humans non-invasively. Currently, a considerable amount of preclinical data are available for several radiotracers and three are under clinical evaluation. We summarise the current status of the evaluation of these tracer molecules and put forward recommendations for their further evaluation.
\end{abstract}

Keywords Beta cell - Beta cell imaging - Diabetes · Exendin · Islet imaging $\cdot$ Islets of Langerhans $\cdot$ PET $\cdot$ Review $\cdot$ SPECT

$\begin{array}{ll}\begin{array}{ll}\text { Abbreviations } \\ \text { \%ID/g }\end{array} & \begin{array}{l}\text { Uptake fraction of the injected dose per } \\ \text { volume of tissue }\end{array} \\ \text { 5-HT } & \text { 5-Hydroxytryptamine (serotonin) } \\ \text { 5-HTP } & \text { 5-Hydroxytryptophan } \\ \text { BP } & \text { Binding potential } \\ \text { DDC } & \text { Aromatic amino acid decarboxylase } \\ \text { DTBZ } & \text { Dihydrotetrabenazine } \\ \text { F-DOPA } & { }^{18} \text { F-labelled L-DOPA } \\ \text { FP } & \text { Fluoropropyl } \\ \text { GLP-1R } & \text { Glucagon-like peptide-1 receptor } \\ \text { IHC } & \text { Immunohistochemical } \\ \text { PET } & \text { Positron emission tomography } \\ \text { PP } & \text { Pancreatic polypeptide } \\ \text { SPECT } & \text { Single photon emission computed tomography } \\ \text { SUR1 } & \text { Sulfonylurea 1 receptor } \\ \text { SUV } & \text { Standardised uptake value } \\ \text { VMAT2 } & \text { Vesicular monoamine transporter 2 }\end{array}$

Olof Eriksson

olof.eriksson@pet.medchem.uu.se

Martin Gotthardt

martin.gotthardt@radboudumc.nl

1 Preclinical PET Platform, Department of Medical Chemistry, Uppsala University, Dag Hammarskjölds väg 14C, 3tr, SE-751 83 Uppsala, Sweden

2 Turku PET Centre, University of Turku, Turku, Finland

3 Department of Biosciences, Åbo Akademi University, Turku, Finland

4 National Institute of Diabetes and Digestive and Kidney Diseases, National Institutes of Health, Bethesda, MD, USA
5 Department of Radiology and Nuclear Medicine, Radboud university medical center, PO Box 9101, $6500 \mathrm{HB}$ Nijmegen, the Netherlands

6 Department of Endocrinology and Diabetology, Medical Faculty, Heinrich Heine University, Düsseldorf, Germany

7 Institute for Clinical Diabetology, German Diabetes Center, Leibniz Center for Diabetes Research, Heinrich Heine University, Düsseldorf, Germany

8 JDRF, Discovery Research, New York, NY, USA

9 Division of Endocrinology, Department of Clinical and Experimental Medicine, University of Parma and AOU of Parma, Parma, Italy 


\section{Introduction}

Beta cell dysfunction, dedifferentiation and death are presumed to be central events in the pathogenesis of both type 1 and type 2 diabetes [1], but there are few direct observations of the fate of beta cells during the development of disease. The clinical course of disease varies considerably. It is sometimes difficult even to distinguish type 1 and type 2 diabetes, leading to the conclusion that diabetes can result from a heterogeneous mixture of pathophysiological processes.

The characterisation of beta cells is currently limited to pancreatic specimens available at autopsy, as in vivo pancreatic biopsy is associated with complications unacceptable in clinical studies [2]. Functional clinical testing measuring insulin/C-peptide concentrations in the blood, for example as a response to a stimulus, does not reflect beta cell mass, only total beta cell function. Reliable imaging biomarkers for noninvasive characterisation of beta cell mass are therefore urgently needed to distinguish between beta cell loss and beta cell (dys)function, and to characterise the natural history of the disease. Based on the available clinical tests for beta cell function, one cannot distinguish loss of beta cell mass, loss of beta cell function, functional recovery under therapy or even beta cell regeneration. A viable cell may also have reduced activity. In a reduced mass of cells, each cell may increase its activity. Salvation therapies may depend on the residual viable beta cell mass, not on the residual total function. The ability to compare beta cell function and beta cell mass can therefore be expected to play a pivotal role in future diabetes research.

In view of the high inter-individual variability of beta cell mass [3], it is clear that exact determination of beta cell mass is required for reliable determination of the relation between beta cell mass and beta cell function. The imaging tools discussed here may not only help to increase our knowledge of pathophysiology but even facilitate the development of personalised therapies to prevent the onset and progression of diabetes [4]. Several radiotracers have now been tested in small clinical trials, but considerable work remains before they can be considered valid biomarkers of beta cell mass. Because so little confirmatory data can be obtained in people, high-quality preclinical experiments remain imperative for the validation process. Here, we suggest standardised preclinical and clinical study protocols for development of these and future beta cellimaging agents.

\section{Principles of radiotracer development for beta cell mass}

Challenges of radiotracer development Radiotracers could potentially be used to target tissues or disease processes in general, but the most successful applications of radiotracers have been for targeting of tumours. Targeting pancreatic beta cells is more challenging, because the islets of Langerhans are small structures, scattered throughout the pancreas $(1-3 \%$ of total volume), that are individually beyond the resolution of positron emission tomography (PET) and single photon emission computed tomography (SPECT) [5]. Furthermore, as knowledge about gradual changes in beta cell mass in relation to beta cell function is essential for further elucidating the pathophysiology of diabetes, the ability to monitor disease progression depends on detecting small changes in beta cell mass. Despite their limited spatial resolution, PET and SPECT are currently the optimum modalities because they can detect very low concentrations of radiotracer in tissue.

Properties of an optimal ligand Antibodies and antibody fragments, peptides and small molecules can be used for in vivo targeting. The total pancreatic uptake of the radiolabelled ligand will be equivalent to beta cell mass only when the radiolabelled targeting agent accumulates specifically in the beta cells and not in other endocrine or exocrine cells. Therefore, ligands should be highly specific for unique targets in the beta cell, and the expression of the target should be constant and insensitive to diabetes or other stresses, such as inflammation.

The circulation time of the radiolabelled ligand, a major factor in obtaining efficient targeting in vivo, is determined by its degradation and the route and dynamics of excretion. A high metabolic stability of the ligand maximises bioavailability and thus accumulation in the target tissue. Large antibodies have a long circulation time because they are cleared slowly from the blood via the liver, whereas peptides and small molecules are usually excreted quickly. For smaller compounds, hydrophilicity largely determines the excretion route; hydrophilic compounds are usually excreted via the kidneys while hydrophobic compounds are predominantly cleared by the liver. Hydrophilic compounds are preferred for beta cell imaging, as the metabolites from hydrophobic compounds are usually excreted from the liver into the intestine, resulting in a high background signal in the abdominal region that may interfere with pancreas imaging. Moreover, hydrophobic tracers might accumulate in the exocrine pancreas and thereby reduce the target-to-background ratio. Tracers that are internalised in the target cells are preferred and can be labelled with so-called 'residualising labels', which are retained in the cells even after degradation of the ligand when no metabolic excretion pathway is present. This 'metabolic trapping' can lead to very high target-to-background ratios if the tracer is efficiently cleared from the blood and non-target tissues.

Requirements for in vivo imaging In contrast to tumour imaging where the target of interest is overexpressed, beta cells and non-neoplastic tissues in general tend to have much lower levels of unique protein targets. In order to achieve sufficient image quality and avoid saturation of the target, it 
may be necessary to use a low dose of ligand, labelled with a very high specific activity (amount of radioactivity [in becquerels] per molecule). It is also important to keep the pharmacological dose low when using biologically active compounds in order to prevent biological or toxic effects.

Tracer uptake can be reported either as concentration (sig$\mathrm{nal} /$ volume) or as integrated pancreas uptake (total signal from pancreas). Radiotracer concentration is expressed as standardised uptake value (SUV) or the fraction of the injected dose per volume of tissue $(\% \mathrm{ID} / \mathrm{g})$ and can be measured at a specified point in time following tracer administration. For an ideal tracer, these measures reflect the concentration of islets or beta cells. This is experimentally straightforward and appropriate for long-lived nuclides where background signal is washed away over time, and for tracers with highly specific binding characteristics. Binding potential (BP) is another measure of concentration and, together with volume of distribution, can be calculated from the time course of the PET signal following tracer injection. The experiment and data analysis are both more challenging for these measures, but BP can distinguish tightly bound tracer from non-specific binding, which can be important for short-lived nuclides to reduce the contribution from background signal. Integrated pancreatic uptake is likely to be more informative, as it reflects total beta cell mass in the pancreas for an ideal tracer. This may require an independent measure of pancreas volume in cases of low pancreatic uptake when delineation of the pancreas by radiotracer uptake alone is challenging [6,7], or when interfering signal is present from high concentrations of excreted tracer metabolites in neighbouring tissues such as renal cortex or intestine.

\section{Identification of molecular targets as surrogate markers for beta cell mass}

\section{Targets for existing radiotracers designed for central ner-} vous system or neuroendocrine applications As beta cells and other pancreatic neuroendocrine cells, but not the pancreatic acini, share many features with neurons, it is conceivable that clinically available PET neuroimaging tracers selectively target beta cells [8]. The high-affinity ligand dihydrotetrabenazine (DTBZ) was radiolabelled for PET 20 years ago, and was proposed as a putative beta cell-imaging ligand when it was shown that its target, vesicular monoamine transporter 2 (VMAT2), was selectively expressed and restricted to the beta cell in pancreas [9]. VMAT2 is localised on intracellular secretory vesicles, where it assists in transporting monoamines. The endogenous precursors for dopamine (L-DOPA) and 5-hydroxytryptamine (5-HT/serotonin) (5-hydroxytryptophan [5-HTP]) have been utilised in neuroimaging studies since the late 1980s. Beta cells also express the synthetic pathways for monoamine neurotransmitters, and pancreatic endocrine tumours exhibit very high uptake of ${ }^{18} \mathrm{~F}$-labelled L-DOPA (F-DOPA) as well as $\left[{ }^{11} \mathrm{C}\right] 5$ HTP. Indeed, benign insulinomas are routinely localised against the pancreatic background using these agents [10]. In addition, it was shown that F-DOPA uptake could differentiate between the focal and diffuse forms of congenital hyperinsulinaemia, which in itself constitutes direct imaging of beta cell mass and dysfunction [11]. The full serotonergic metabolic pathway has recently been described in the pancreatic beta cell, as has been the expression of several serotonin receptors in beta, alpha and delta cells $[12,13]$.

Established targets for glucose-lowering treatments Drugs designed to stimulate insulin secretion have also proven to be attractive starting points for the development of beta cellimaging agents. Sulfonylurea 1 receptor (SUR1) is localised on the beta cell, constitutes an effective target for diabetes therapy and could therefore be a target for imaging [14]. Several SUR1-targeting agents have been described, but despite the promising concept, no agents have been exhaustively evaluated. Glucagon-like peptide-1 receptor (GLP-1R) has been a molecular target of high interest for treating type 2 diabetes since the discovery of the peptide agonist exendin-4. Unlike the endogenous peptide, exendin- 4 is resistant to degradation by dipeptidyl peptidase IV (DPP-IV) and therefore exhibits higher in vivo stability. Its density on beta cells [15], combined with its negligible expression on pancreatic acini [16] and islet alpha cells [17], has made GLP-1R a highly promising target.

Screening for novel targets using high-throughput approaches Because of its unique biology and function, the human beta cell is likely to express many specific molecular targets that are absent from the remaining pancreas. Approaches such as proteomic and transcriptomic analyses can be used to screen pancreas cell types for unique beta cell targets [9]. Recent publications using informatics and public access databases have identified several beta cell-restricted molecular protein targets $[18,19]$. The small molecules or peptides that bind to these novel targets and are suitable for radiolabelling and clinical imaging applications remain to be identified. However, given the advances in high-throughput screening for small molecule ligands, and biotechnology to produce tailored affibodies, nanobodies and diabodies, this approach seems promising. As proof of principle, Table 1 presents an assessment of islet specificity of established imaging targets using publicly available 'omics' data.

\section{Preclinical evaluation of beta-cell-selective agents}

A flow scheme for putative agents There are several absolute requirements that constitute a minimum assessment of the translational value of beta cell-imaging agents prior to clinical evaluation (Fig. 1). Immunohistochemical (IHC) assessment 
Table 1 In vitro evaluation of leading potential beta cell-imaging agents according to points 1 and 2 in Fig. 1

\begin{tabular}{|c|c|c|c|c|}
\hline Study type & Cell/tissue & {$\left[{ }^{18} \mathrm{~F}\right] \mathrm{FP}-\mathrm{DTBZ}(\mathrm{VMAT} 2)$} & Labelled exendin-4 (GLP-1R) & {$\left[{ }^{11} \mathrm{C}\right] 5-\mathrm{HTP}(\mathrm{DDC})$} \\
\hline \multicolumn{5}{|c|}{ Target receptor specificity } \\
\hline Cell & INS-1 & - & Yes [51] & Yes [12] \\
\hline Cell & Human islets & Yes $[9,28]$ & - & Yes [12] \\
\hline In vitro & INS-1 & - & Yes [52] & - \\
\hline Autoradiography & Pancreas & Yes [28] & Yes [53] & - \\
\hline \multicolumn{5}{|l|}{ Islet selectivity } \\
\hline Cell & INS- 1 to PANC1 ratio & - & - & Yes [12] \\
\hline Cell & Human islets to exocrine ratio & Yes [9]/No [28] & - & Yes (15-fold) [12] \\
\hline In vitro & Pancreas (islets to exocrine ratio) & No $[28,37]$ & Yes [53] & - \\
\hline Autoradiography & Pancreas (islets to exocrine ratio) & No $[28,37]$ & Yes [53] & - \\
\hline
\end{tabular}

Target receptor specificity refers to radiotracer binding being receptor-specific (e.g. if it can be abolished by pretreatment with cold compound in excess) rather than consisting of off-target binding in cell models or on pancreatic sections. The islet selectivity in cell and in vitro autoradiography studies refers to demonstration of selective targeting of islets compared with exocrine pancreatic tissue

shows that the molecular target co-localises with insulin in pancreatic sections and is therefore present and restricted to the beta cell. Additional tests are needed to show that the imaging ligand binds to its putative target in the beta cell (steps 1 and 3 in Fig. 1), and lacks appreciable specific binding to nontarget molecules or non-specific binding elsewhere in the pancreas (steps 2 and 4). Although success for steps 1 and 2 can be implied from data in tissue slices using the imaging ligand decorated with any suitable label (such as a fluorescent tag), it must also be shown for the radiolabelled imaging ligand itself, preferably using autoradiography, as radiolabelling may significantly alter binding properties.

The binding of a given ligand to isolated cells or tissues in vitro does not necessarily predict its behaviour in vivo, which depends on delivery to the target tissue as well as specific and non-specific binding. If the radiotracer labels a cell via metabolic trapping, the signal depends on the specificity and speed of internalisation and on the ability to concentrate the radiotracer within the cell, which may differ between cell types. Demonstration of signal in pancreas following in vivo tracer administration, and target specificity of that signal, e.g. by displacing the radioligand with cold ligand (step 3), must be followed by ex vivo evaluation of tracer in specific cell types of the target tissue (step 4a of Fig. 1). This should be followed by demonstration that tracer uptake is significantly reduced in an animal model of beta cell loss (step 4b).

Following the evaluation procedures outlined in Fig. 1, a correlation between in vivo pancreas tracer uptake and actual beta cell mass must be demonstrated. This can be done in the native pancreas or in islet grafts (preferably in humanised animal models). Currently, the reference standard requires IHC determination of beta cell volume in several slices of pancreatic tissue, and calculation of the total pancreatic beta cell mass (or islet graft beta cell mass) based on per slice beta cell volume. If feasible, the lack of correlation with alpha cell mass should also be demonstrated in suitable animal models of beta cell ablation [17].

Preclinical assessment of tracers should also include validation in animal models of diabetes other than chemical beta cell ablation models in order to assess the influence of, for example, inflammation (such as insulitis in type 1 diabetes models) or glucotoxicity on the expression of the target receptor on beta cells, and potential overexpression under such conditions in other cell types. Finally, animal models with beta cell dysfunction should allow validation of the tracer molecule as a marker of beta cell mass independent of beta cell function.

Agents currently in clinical testing Radiolabelled beta cellimaging agents for three different molecular targets have undergone initial clinical validation. These are $\left[{ }^{18} \mathrm{~F}\right]$ fluoropropyl (FP)-DTBZ (which targets VMAT2), radiolabelled exendin-4 $\left({ }^{68} \mathrm{Ga}-\right.$ and ${ }^{111} \mathrm{In}$-labelled analogues targeting GLP-1R) and $\left[{ }^{11} \mathrm{C}\right] 5-\mathrm{HTP}$ (which traces serotonin biosynthesis via aromatic amino acid decarboxylase [DDC]). The literature describing preclinical assessment of these agents is reviewed below with regard to the experimental procedures outlined in Fig. 1.

IHC evidence implies that VMAT2 is largely confined to beta cells and pancreatic polypeptide (PP) cells in the human pancreas [7], GLP-1R appears to be beta cell-specific (although expression in alpha cells has been discussed but not finally proven) [17] and the serotonin synthetic pathway is found in beta and alpha cells [6]. In vitro evaluation of tracer specificity for its target was successful for all three candidates using primary islets, beta cell models or in vitro autoradiography. Each tracer exhibits low to negligible off-target binding in the pancreas (Table 2). To varying degrees, all three tracer classes also exhibit specific receptor targeting combined with low non-displaceable (off-target or non-specific) binding in pancreas in vivo, in rodents or large animal models including non-human primates (Table 3 ). There are species differences: 


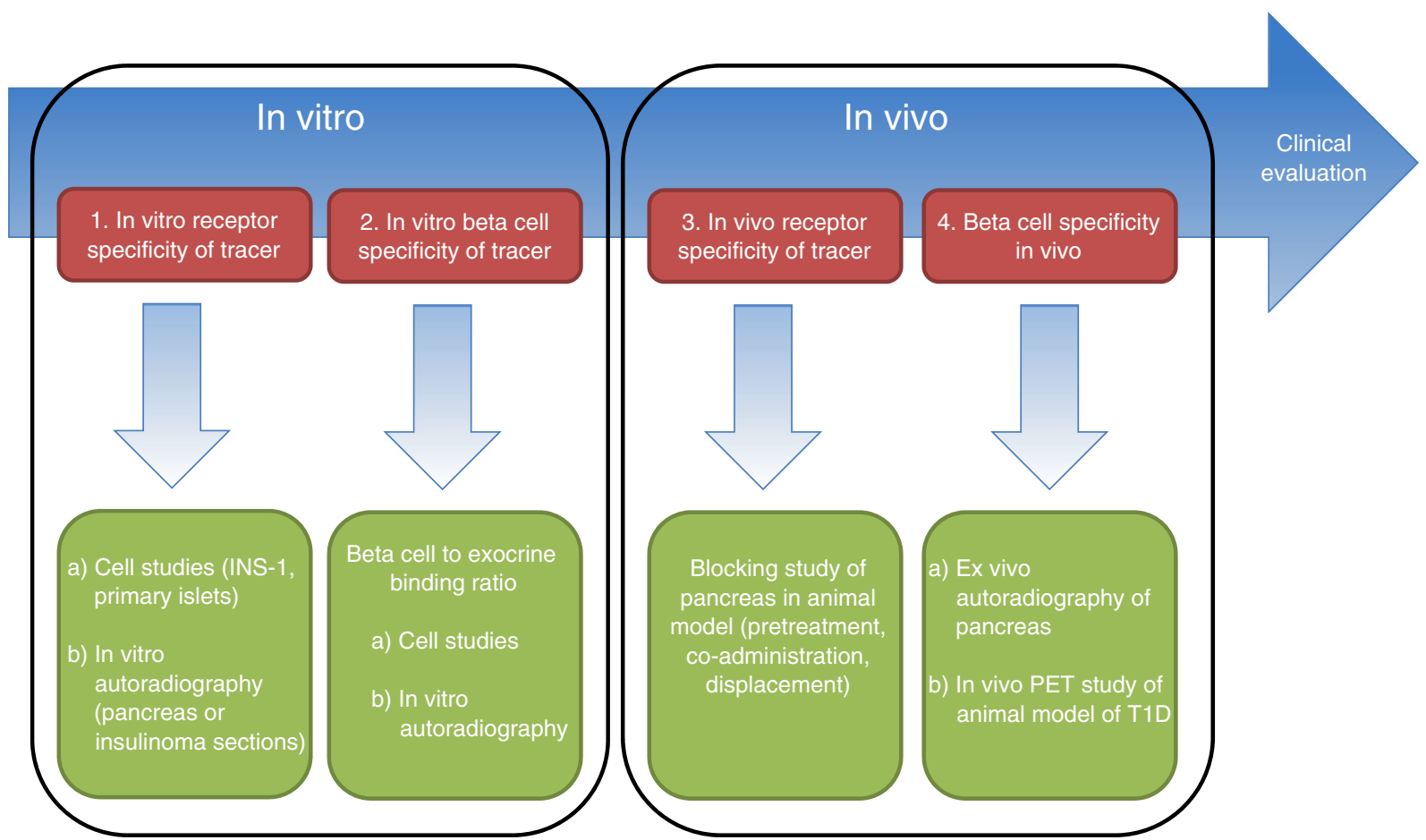

Fig. 1 Proposed flow scheme for evaluating putative beta cell-imaging agents. Two strict mandatory requirements can be defined. First, the radioligand must have selectivity for its intended target, with low to negligible off-target binding in tissue. Second, the radioligand must accumulate specifically in the beta cells within the pancreas. The first requirement can be assessed in vitro by binding experiments in beta cell models or pancreatic sections in vitro, where off-target binding is determined by pre-blocking of the target (1). The in vitro assessment of beta cell-selective accumulation can be performed by comparing binding in a model of beta cells directly with binding in a model of the exocrine pancreas, or directly on human pancreatic sections (2). The in vivo assessment of radiotracer target selectivity is performed analogously, as in vitro, by demonstrating that target tissue binding can be abolished by pretreatment with a blocking agent (3). Finally, the in vivo beta cell selectivity of accumulation can be determined directly by ex vivo autoradiography of pancreatic sections removed after administration of the radioligand, or inferred indirectly by demonstrating abolished pancreatic uptake following beta cell ablation (4). For proof of principle, a linear relationship between the in vivo accumulation and ex vivo assessment of pancreatic beta cell mass should be demonstrated. T1D, type 1 diabetes labelled exendin-4 binds rodent, but not pig, islets [20]. VMAT2 is more easily demonstrated in rat, pig and nonhuman primates than in mice [21].

It is of crucial importance to demonstrate that this specific in vivo binding is confined to the islets. Ex vivo autoradiographic measurements following in vivo label administration should be considered a gold standard as the resolution, $(<100 \mu \mathrm{m})$ for most nuclides, enables clear detection of individual islets of Langerhans. Islet homing has thus been demonstrated for ${ }^{68} \mathrm{Ga}-[22],{ }^{111} \mathrm{In}$ - [16] and ${ }^{177} \mathrm{Lu}$-labelled exendin-4 [23]. For short-lived nuclides such as ${ }^{11} \mathrm{C}$, this technique becomes more challenging because of the rapid loss of signal; Di Gialleonardo et al could not detect islet-specific binding of $\left[{ }^{11} \mathrm{C}\right] 5-\mathrm{HTP}$ in rat during baseline conditions, but inhibition of monoamine oxidase (MAO)-mediated degradation of $\left[{ }^{11} \mathrm{C}\right] 5-\mathrm{HT}$ did yield an islet-specific signal [24]. Isletspecific uptake was found in mice using a tritiated 5-HTP isotopologue [25]. Ex vivo autoradiography showing isletspecific accumulation of radiolabelled DTBZ in the pancreas has not yet been published.

Ex vivo autoradiography using PET and SPECT nuclides cannot easily distinguish between different islet cell types, as spatial resolution is limited by the energy of the emitted positrons/photons. However, for an optimal ligand, total beta cell ablation should abolish any pancreatic signal, or at least reduce uptake to a degree comparable with that seen with complete receptor blockade in non-diabetic animals. This has been shown both in vivo and ex vivo in rats with labelled exendin-4 [26] and $\left[{ }^{11} \mathrm{C}\right] 5$-HTP [12]. Studies in rat models of type 1 diabetes show a decrease in the pancreatic signal from $\left[{ }^{18} \mathrm{~F}\right] \mathrm{FP}-\mathrm{DTBZ}$, but not to levels corresponding to complete receptor blockade [27]. If the receptor concerned is expressed in cells other than beta cells, displacement studies in beta cell ablation models may be able to demonstrate lack of specificity, as there will be residual specific binding. However, care must be taken when interpreting these data, as beta cell ablation itself may change target receptor levels in non-beta endocrine or exocrine cells. In that case, autoradiography in combination with immunohistochemistry would be needed to demonstrate specificity. Pig models of diabetes have shown conflicting results for $\left[{ }^{18} \mathrm{~F}\right]$ FP-DTBZ and labelled exendin- 4 , possibly because of model differences in pancreatic target expression $[20,28]$. 
Table 2 In vivo evaluation of leading potential beta cell-imaging agents according to points 3 and 4 in Fig. 1

\begin{tabular}{lll}
\hline In vivo system & {$\left[{ }^{18}\right.$ F $]$ FP-DTBZ(VMAT2) } & $\begin{array}{l}\text { Labelled exendin-4 } \\
\text { (GLP-1R) }\end{array}$ \\
\hline
\end{tabular}

\begin{tabular}{|c|c|c|c|}
\hline \multicolumn{4}{|l|}{ Target receptor specificity } \\
\hline \multicolumn{4}{|l|}{ In vivo blocking } \\
\hline Mouse & - & Yes $[51,52]$ & - \\
\hline Mouse (INS-1) & - & Yes $[51,52]$ & - \\
\hline Rat & Yes [54] & Yes [26] & - \\
\hline Pig & - & Yes [20] & - \\
\hline Non-human primate & Yes [38] & Yes [26] & Yes [12] \\
\hline \multicolumn{4}{|l|}{ Islet selectivity } \\
\hline \multicolumn{4}{|c|}{ Ex vivo autoradiography (islet to exocrine ratio) } \\
\hline Mouse & - & Yes $[55,56]$ & Yes [25] \\
\hline Rat & - & Yes (50-fold) $[16,22,23]$ & No [24] \\
\hline Pig & - & $\mathrm{No}^{\mathrm{a}}$ & - \\
\hline \multicolumn{4}{|c|}{ Type 1 diabetes model (decrease in signal compared with control) } \\
\hline Mouse & No [21] & Yes $[55,56]$ & - \\
\hline Rat & Yes $[27,57]$ & Yes [26] & Yes [12] \\
\hline Pig & - & No [20] & - \\
\hline
\end{tabular}

The target receptor specificity here refers to the radiotracer binding being receptor-specific in vivo in animal models rather than consisting of off-target binding in the pancreas. The in vivo islet selectivity refers to accumulation in islets rather than in the exocrine pancreas in living pancreatic tissue. This is commonly assessed either directly by ex vivo autoradiograms of pancreatic sections or indirectly by demonstrating a decreased pancreatic signal in beta cell ablation models (type 1 diabetes). ${ }^{\mathrm{a}} \mathrm{O}$. Eriksson, personal communication

\section{Results of clinical trials with radiotracers}

VMAT2 In clinical studies of $\left[{ }^{11} \mathrm{C}\right] \mathrm{DTBZ}[29]$ and $\left[{ }^{18} \mathrm{~F}\right] \mathrm{FP}$ DTBZ [30,31], the fluorinated compound was shown to yield superior results because of its higher affinity for VMAT2. Cross-sectional studies using $\left[{ }^{18} \mathrm{~F}\right] \mathrm{FP}-\mathrm{DTBZ}$ measured decreases between $38 \%$ and $40 \%$ in SUV and BP [30], and $26 \%$ in BP [31] in pancreases of patients with longstanding type 1 diabetes $(n=7-8)$ in comparison with non-diabetic humans $(n=9-14)$. Signal was distributed heterogeneously across the pancreas. Because the pancreas volume was smaller in participants with type 1 diabetes, the total integrated pancreatic uptake was decreased in type 1 diabetes by $59 \%$ [30] and $63 \%$ [31] and correlated well with stimulated C-peptide release $[30,31]$. Signal in the pancreases of three participants with longstanding type 2 diabetes (reported as BP) tended to decrease as well, but not significantly [31]. The BP test-retest variability in two people with type 1 diabetes and five without diabetes averaged $9.4 \%$ [31].

Serotonin biosynthesis In a cross-sectional study, the pancreatic uptake of $\left[{ }^{11} \mathrm{C}\right] 5-\mathrm{HTP}$ measured as concentration $(\% \mathrm{ID} / \mathrm{g})$
Table 3 Summary of results from clinical cross-sectional studies of three leading potential beta cell mass-imaging agents

\begin{tabular}{|c|c|c|c|c|}
\hline \multirow[t]{2}{*}{ Variable } & \multicolumn{2}{|l|}{$\left[{ }^{18} \mathrm{~F}\right] \mathrm{FP}-\mathrm{DTBZ}$} & \multirow{2}{*}{$\begin{array}{l}{ }^{111} \text { In-exendin-4 } \\
{[16]}\end{array}$} & \multirow{2}{*}{$\begin{array}{l}{\left[{ }^{11} \mathrm{C}\right] 5-\mathrm{HTP}} \\
{[6]}\end{array}$} \\
\hline & $\begin{array}{l}\text { Normandin et al } \\
{[30]}\end{array}$ & $\begin{array}{l}\text { Freeby et al } \\
{[31]}\end{array}$ & & \\
\hline \multicolumn{5}{|l|}{ Number of individuals } \\
\hline Healthy & 9 & 14 & 5 & 9 \\
\hline With type 1 diabetes & 7 & 8 & 5 & 10 \\
\hline \multicolumn{5}{|c|}{ Signal decrease $(\%)$ in type 1 diabetes } \\
\hline $\begin{array}{l}\text { Mean concentration in } \\
\text { pancreas } \\
\text { Integrated pancreatic up }\end{array}$ & 40 & 26 & - & 39 \\
\hline Mean & 59 & 63 & 62 & 66 \\
\hline Maximal & 78 & 79 & 96 & 93 \\
\hline
\end{tabular}

Values indicate signal decrease (\%) in individuals with type 1 diabetes compared with non-diabetic individuals 
was reduced by $39 \%$ and total pancreas uptake was reduced by $66 \%$ in ten humans with longstanding type 1 diabetes compared with nine non-diabetic volunteers. In two of the individuals with type 1 diabetes, total uptake decreased by more than $90 \%$. Despite this, islet alpha cell uptake of $\left[{ }^{11} \mathrm{C}\right] 5$-HTP could contribute to the residual pancreas signal observed in type 1 diabetes [25]. A retrospective study of patients who underwent repeated PET scanning for suspected neuroendocrine tumour was reported in the same paper. Two patients with type 2 diabetes exhibited reduced signal $(\% \mathrm{ID} / \mathrm{g})$ compared with eight individuals without diabetes, and the test-retest variability in non-diabetic volunteers was $6.4 \pm 1.7 \%$. One of the type 2 diabetes patients was examined four times over 30 months and exhibited a progressive loss of half of the original pancreas signal, perhaps indicating progression of disease [6].

GLP-1R Kidney uptake of ${ }^{111}$ In-labelled exendin-4 impairs the visibility of the pancreatic tail, but a quantitative SPECT imaging protocol allows for absolute quantification of pancreatic uptake (this problem does not occur in PET imaging because of better spatial resolution). As with other tracers, pancreatic uptake shows substantial inter-individual variability and overlap between diabetic and non-diabetic individuals. The average integrated pancreatic uptake in five individuals with type 1 diabetes was $62 \%$ lower compared with that of five healthy volunteers matched for age, BMI and sex. Signal remained near background levels in three of the type 1 diabetes patients, but at least one was higher than the average seen in healthy volunteers [16]. The appearance of pancreas signal inversely correlated with disease duration.

\section{Critical review of clinical results based on preclinical val-} idation All three classes of radiolabelled ligand that have been clinically tested in small populations show substantial but highly variable pancreatic tracer uptake in healthy controls (ranges from approximately threefold [6, 30] to sixfold [16]). There is reduced but also highly variable uptake in individuals with type 1 diabetes (Table 3 ), and overlap between these two ranges. Results using $\left[{ }^{18} \mathrm{~F}\right] \mathrm{FP}-\mathrm{DTBZ}$ and $\left[{ }^{11} \mathrm{C}\right] 5-\mathrm{HTP}$ are reproducible to $<10 \%$ variance within an individual. Prior to additional clinical investigation, how can these data, particularly the residual signal found in type 1 diabetes pancreas with all agents, be interpreted? Recent observations made in cadaveric pancreas from diabetic and nondiabetic people are useful, and all available preclinical data obtained using these agents in cells, animal models, isolated human islets and pancreas slices should be considered.

Beta cell mass measured in cadaveric pancreas appears to be negatively correlated with age and perhaps positively correlated with BMI. Despite these trends, the results imply a strikingly large variability in people who are metabolically normal as well as in people with diabetes (tenfold range [3]). Likewise, it appears that beta cells can be present and associated with inflammatory cell infiltrates even decennia after the onset of type 1 diabetes $[32,33]$. Large changes in pancreas size accompany type 1 diabetes even before clinical diagnosis [34], indicating disease-related changes in the exocrine pancreas of a nature that is not yet understood [34, 35]. Although not confirmed in humans, there is evidence for plasticity among islet cell types in metabolically stressed mice [36]. Therefore, the large range of pancreas signal found in PET and SPECT studies of healthy and type 1 diabetes people should not be surprising. However, it would still be expected that a relevant percentage of individuals with type 1 diabetes should show a signal decrease $>80-90 \%$ for a perfect tracer of beta cell mass.

None of the 15 people with type 1 diabetes studied with $\left[{ }^{18} \mathrm{~F}\right]$ FP-DTBZ showed a decrease of this magnitude [30, 31]. It is possible that, despite expressing tracer concentration in terms of BP, residual non-specific binding occurs [28, 37]. However, a recent study in baboons showed that such nonspecific $\left[{ }^{18} \mathrm{~F}\right]$ FP-DTBZ binding was negligible in the pancreas [38]. The residual signal could be due to off-target binding to another population of receptors in the exocrine pancreas [37, 39], or to binding to VMAT2 in endocrine cells other than the beta cell. Islet PP cells express VMAT2 and could account for at least some of the residual signal in type 1 diabetes [7, 40]. PP cells are $\sim 0.81 \%$ of pancreas volume overall, but are heterogeneously distributed, and make up $1.58 \%$ of the pancreatic head and $0.41-0.58 \%$ of the body and tail, where $89-96 \%$ of VMAT2 staining co-localises with insulin [7]. It has therefore become the practice to report $\left[{ }^{18} \mathrm{~F}\right] \mathrm{FP}-\mathrm{DTBZ}$ signal data for the head, body and tail of the pancreas separately, and to rely more heavily on the signal from the body and tail to assess beta cell mass. More work in human pancreas is needed to understand what fraction of the $\left[{ }^{18} \mathrm{~F}\right] \mathrm{FP}-\mathrm{DTBZ}$ signal is derived from beta cells, what fraction comes from the PP cells and whether there is significant signal coming from other islet cells or exocrine tissue. This question needs to be answered, preferably in human tissue, in order to rate the relevance of $\left[{ }^{18} \mathrm{~F}\right] \mathrm{FP}-\mathrm{DTBZ}$ for diabetes imaging.

$\left[{ }^{11} \mathrm{C}\right] 5-\mathrm{HTP}$ and exendin-4 radiotracer uptake in the pancreas correlate with actual beta cell mass measured in rodent models of type 1 diabetes using immunohistochemistry [12, 16]. Both off-target specific and non-specific binding are negligible in the non-human primate pancreas $[12,26]$. Labelled exendin-4 appears confined to the beta cell and may be an effective tracer for beta cell mass, while the serotonin synthesis pathway is found in both beta and alpha cells [25]. $\left[{ }^{11} \mathrm{C}\right] 5$-HTP may therefore be a better marker for islet, rather than beta cell, mass.

Because of metabolic trapping, $\left[{ }^{11} \mathrm{C}\right] 5$-HTP uptake may be sensitive to cell function, and perhaps alpha cell $\left[{ }^{11} \mathrm{C}\right] 5-\mathrm{HTP}$ retention is much lower than that for beta cells under the conditions studied (as inferred from Ekholm et al [25]); at least two of the ten diabetic individuals showed $>90 \%$ reduction from control levels, as would be expected only for a tracer that 
faithfully reports uniquely on beta cell mass, although this reduction could also be caused by loss of beta and alpha cells. This question needs further investigation. More experience is needed with this promising tracer in human pancreas. GLP-1R is likely to be expressed only in beta cells of the islet, and although exendin-4 alters alpha cell glucagon secretion, this may be due to indirect effects [17]. A significant fraction of the individuals with type 1 diabetes studied had very little residual signal, and therefore radiolabelled exendin- 4 is likely to be the best current candidate biomarker for pure beta cell mass. The use of the long-lived SPECT radionuclide ${ }^{111}$ In makes it ideal for validation studies, but also constrains image spatial resolution, with the high overlapping signal from the kidney making quantification difficult [16]. It may be that exendin-4 labelled with a PET tracer (such as ${ }^{68} \mathrm{Ga}$ or ${ }^{18} \mathrm{~F}$ ) at sufficiently high specific activity could allow for in vivo human kinetic studies with appropriate time and spatial resolution to further explore the properties of this class of tracers.

\section{Next steps for clinical validation}

A quantitative biomarker must exhibit sufficient sensitivity, reproducibility, specificity and accuracy to represent the intended biological phenomenon. The specificity and reproducibility of $\left[{ }^{18} \mathrm{~F}\right] \mathrm{FP}-\mathrm{DTBZ}$, labelled exendin-4 and $\left[{ }^{11} \mathrm{C}\right] 5$ HTP have been addressed in preclinical development. Early clinical studies indicate that all probably have sufficient sensitivity to detect the significant changes in beta cell mass expected in type 1 diabetes. However, the limits for detecting mass and changes in mass need to be explored. One indirect approach would be to image more groups of individuals expected to have different beta cell concentrations. Five such groups, from least to most beta cell mass, might be: (1) patients with early childhood-onset type 1 diabetes, with more than 40 years of disease [41]; (2) middle-aged patients with type 2 diabetes [3, 42]; (3) elderly individuals with normal glucose tolerance [3]; (4) lean individuals in their 20s with normal glucose tolerance [3, 43, 44]; and (5) obese individuals with normal glucose tolerance [42].

In addition, studies to be performed might include longitudinal imaging in newly diagnosed individuals with type 1 diabetes where an expected decline in beta cell mass over a 3-5 year period might define the ability of a tracer to measure gradual beta cell loss.

Reproducibility measured as test-retest variability in nondiabetic, type 1 diabetes and type 2 diabetes individuals is similar to other PET/SPECT tracers for $\left[{ }^{18} \mathrm{~F}\right] \mathrm{FP}-\mathrm{DTBZ}$ and $\left[{ }^{11} \mathrm{C}\right] 5-\mathrm{HTP}$, and has not yet been reported for labelled exendin-4. Reproducibility should also be tested in people with reduced glucose tolerance or insulin sensitivity, or in very obese individuals with normal glucose tolerance.
Establishing accuracy remains the most important and most difficult goal in clinical validation. The gold standard is direct comparison of in vivo radiotracer images with histological or autoradiographic data in excised tissue. However, biopsying the human pancreas following in vivo imaging is clinically unacceptable. A reference model might instead be whole human perfused pancreas obtained from brain-dead donors [45], although the few available pancreases are badly needed for treatment of disease via whole organ or islet transplantation. A more feasible approach is to study patients for whom resection of pancreatic tumour is planned. Tracer uptake normalised to organ volume (e.g. \% ID/g tissue) can then be compared with a histological measure of beta cell (or islet) density $[3,46,47]$ in excised healthy tissue surrounding the tumour. Direct microautoradiographic visualisation of the radioligand in such tissue would be particularly useful to validate that the radiotracer, when infused into a person, is specific for islet cells. This can be done when using radionuclides such as ${ }^{111}$ In with a half-life measured in days, but is challenging with ${ }^{11} \mathrm{C}$ and ${ }^{18} \mathrm{~F}$ which have half-lives of around 20 and $110 \mathrm{~min}$, respectively. Islet transplantation could be a model for assessing whether an imaging biomarker accurately and specifically reports beta cell mass, because a measured number of islets are injected either into the portal circulation to reside in the liver or, more recently, into the bone marrow [48], and beta cell fraction can easily be assessed in a reserved portion of the isolated islets. However, factors such as inflammation may influence the results. Therefore, data have to be assessed thoroughly to avoid false interpretation.

A perfect biomarker of beta cell mass would be unaffected by beta cell function. This can be tested by conducting the imaging experiment with and without a glucose challenge designed to elicit insulin secretion. If the results are altered by the glucose challenge, it will be important to identify and specify the conditions under which the biomarker accurately reports beta cell mass. The likelihood that secretion of insulin or other hormones affects tracer uptake depends on the specific protein or pathway targeted. For instance, ligands for protein targets may compete less well when the endogenous ligand concentration is elevated. 5-HTP is converted to 5-HT/serotonin, concentrated inside the large dense core vesicles of beta cells and cosecreted with insulin [49]. Therefore, $\left[{ }^{11} \mathrm{C}\right] 5$-HT uptake might be expected to be sensitive to beta cell function. Likewise, a glucagon secretagogue may help quantify the fraction of signal contributed by alpha cells $[12,25]$. Furthermore, $\left[{ }^{11} \mathrm{C}\right] 5-\mathrm{HT}$ released during beta cell exocytosis may bind to 5-HT receptors present on the human islets resulting in a pancreatic PET signal undistinguishable from that of metabolically trapped $\left[{ }^{11} \mathrm{C}\right] 5$ HT. Some 5-HT receptors are upregulated in type 2 diabetes, but how this will affect $\left[{ }^{11} \mathrm{C}\right] 5$-HTP PET imaging output is unknown [13]. Another example is GLP-1, which may be elevated postprandially and thus decrease binding and uptake of radiolabelled exendin-4 derivatives via the GLP-1R; GLP-1R 
scanning might therefore better be performed in individuals in the fasting state. Increased levels of endogenous GLP-1 have also been reported in patients receiving metformin treatment, which might therefore also have to be discontinued for GLP-1R scanning [50].

Results of clinical trials of prospective islet or beta cellimaging agents should be standardised in order to facilitate comparison of results between sites and between different tracers. It is difficult to choose one output variable, as protocols and methods of analysis depend on the nuclide used (SPECT or PET). However, we suggest that pancreatic tracer uptake be reported both as concentration and integrated pancreas uptake, and that pancreatic volume also be reported. Because the primary goal is absolute beta cell mass, we propose integrated pancreatic uptake as the 'lead output'.

\section{Conclusion}

A toolbox of PET/SPECT imaging biomarkers is under development that has the potential to change the way we look at the pathophysiology of islet function in the context of diabetes. Among these, radiolabelled exendin-4 has the highest sensitivity and specificity for beta cells. Although some open questions remain concerning potential uptake in the exocrine pancreas, the clinical data show a reduction of pancreatic tracer uptake to background levels in some type 1 diabetes patients, implying that uptake in the exocrine pancreas may be negligible in humans. The in vivo specificity of $\left[{ }^{18} \mathrm{~F}\right] \mathrm{FP}-\mathrm{DTBZ}$ for beta cells has not yet been demonstrated, but this would be required in order to demonstrate that this tracer can serve as a good biomarker of human beta cell mass. $\left[{ }^{11} \mathrm{C}\right] 5$-HTP may reflect total endocrine, rather than beta cell, mass. If proved through validation studies in humans to be a robust biomarker for islet mass, the combination of $\left[{ }^{11} \mathrm{C}\right] 5$-HTP and radiolabelled exendin-4 imaging in the same individuals may help distinguish between cell death and dedifferentiation, and thereby contribute to our understanding of the natural history of the beta cell and its fate in diabetes.

While further preclinical evaluation is needed, work in cell and animal models can never fully predict the behaviour of prospective disease biomarkers and their potential to contribute to diabetes research and treatment. The time is ripe for in-depth clinical validation studies of pancreatic beta cell-imaging agents in humans, preferably linking the results of imaging with clinical outcome variables. Such data are expected to enable optimised patient stratification, potentially allowing more individualised treatment of diabetes in the future.

Duality of interest The authors declare that there is no duality of interest associated with this manuscript.
Contribution statement All authors were responsible for drafting the article and revising it critically for important intellectual content. All authors approved the version to be published.

\section{References}

1. Tuomi T, Santoro N, Caprio S, Cai M, Weng J, Groop L (2014) The many faces of diabetes: a disease with increasing heterogeneity. Lancet 383:1084-1094

2. Krogvold L, Edwin B, Buanes T et al (2014) Pancreatic biopsy by minimal tail resection in live adult patients at the onset of type 1 diabetes: experiences from the DiViD study. Diabetologia 57:841843

3. Rahier J, Guiot Y, Goebbels RM, Sempoux C, Henquin JC (2008) Pancreatic beta-cell mass in European subjects with type 2 diabetes. Diabetes Obes Metab 10(Suppl 4):32-42

4. Gotthardt M, Eizirik DL, Cnop M, Brom M (2014) Beta cell imaging - a key tool in optimized diabetes prevention and treatment. Trends Endocrinol Metab 25:375-377

5. Sweet IR, Cook DL, Lernmark A, Greenbaum CJ, Krohn KA (2004) Non-invasive imaging of beta cell mass: a quantitative analysis. Diabetes Technol Ther 6:652-659

6. Eriksson O, Espes D, Selvaraju RK et al (2014) Positron emission tomography ligand [11C]5-hydroxy-tryptophan can be used as a surrogate marker for the human endocrine pancreas. Diabetes 63 : 3428-3437

7. Freeby M, Ichise M, Harris PE (2012) Vesicular monoamine transporter, type 2 (VMAT2) expression as it compares to insulin and pancreatic polypeptide in the head, body and tail of the human pancreas. Islets 4:393-397

8. Karlsson F, Antonodimitrakis PC, Eriksson O (2015) Systematic screening of imaging biomarkers for the Islets of Langerhans, among clinically available positron emission tomography tracers. Nucl Med Biol 42:762-769

9. Maffei A, Liu Z, Witkowski P et al (2004) Identification of tissuerestricted transcripts in human islets. Endocrinology 145:45134521

10. Orlefors H, Sundin A, Garske U et al (2005) Whole-body (11)C-5hydroxytryptophan positron emission tomography as a universal imaging technique for neuroendocrine tumors: comparison with somatostatin receptor scintigraphy and computed tomography. J Clin Endocrinol Metab 90:3392-3400

11. Mohnike K, Blankenstein O, Minn H, Mohnike W, Fuchtner F, Otonkoski T (2008) [18F]-DOPA positron emission tomography for preoperative localization in congenital hyperinsulinism. Horm Res 70:65-72

12. Eriksson O, Selvaraju RK, Johansson L et al (2014) Quantitative imaging of serotonergic biosynthesis and degradation in the endocrine pancreas. J Nucl Med 55:460-465

13. Bennet H, Balhuizen A, Medina A et al (2015) Altered serotonin (5HT) $1 \mathrm{D}$ and $2 \mathrm{~A}$ receptor expression may contribute to defective insulin and glucagon secretion in human type 2 diabetes. Peptides 71:113-120

14. Schneider $\mathrm{S}$, Feilen PJ, Schreckenberger $\mathrm{M}$ et al (2005) In vitro and in vivo evaluation of novel glibenclamide derivatives as imaging agents for the non-invasive assessment of the pancreatic islet cell mass in animals and humans. Exp Clin Endocrinol Diabetes 113: 388-395

15. Tornehave D, Kristensen P, Romer J, Knudsen LB, Heller RS (2008) Expression of the GLP-1 receptor in mouse, rat, and human pancreas. J Histochem Cytochem 56:841-851 
16. Brom M, Woliner-van der Weg W, Joosten L et al (2014) Noninvasive quantification of the beta cell mass by SPECT with (111)In-labelled exendin. Diabetologia 57:950-959

17. Brom M, Joosten L, Frielink C, Boerman O, Gotthardt M (2015) (111)In-exendin uptake in the pancreas correlates with the beta-cell mass and not with the alpha-cell mass. Diabetes 64:1324-1328

18. Bouckenooghe T, Flamez D, Ortis F, Goldman S, Eizirik DL (2010) Identification of new pancreatic beta cell targets for in vivo imaging by a systems biology approach. Curr Pharm Des 16:1609-1618

19. Lindskog C, Korsgren O, Ponten F, Eriksson JW, Johansson L, Danielsson A (2012) Novel pancreatic beta cell-specific proteins: antibody-based proteomics for identification of new biomarker candidates. J Proteome 75:2611-2620

20. Nalin L, Selvaraju RK, Velikyan I et al (2014) Positron emission tomography imaging of the glucagon-like peptide-1 receptor in healthy and streptozotocin-induced diabetic pigs. Eur J Nucl Med Mol Imaging 41:1800-1810

21. Virostko J, Henske J, Vinet L et al (2011) Multimodal image coregistration and inducible selective cell ablation to evaluate imaging ligands. Proc Natl Acad Sci U S A 108:20719-20724

22. Mikkola K, Yim CB, Fagerholm V et al (2014) $64 \mathrm{Cu}-$ and $68 \mathrm{Ga}-$ labelled [Nle(14), Lys(40)(Ahx-NODAGA)NH2]-exendin-4 for pancreatic beta cell imaging in rats. Mol Imaging Biol 16:255-263

23. Velikyan I, Bulenga TN, Selvaraju R et al (2015) Dosimetry of [(177)Lu]-DO3A-VS-Cys(40)-Exendin-4 - impact on the feasibility of insulinoma internal radiotherapy. Am J Nucl Med Mol Imaging 5:109-126

24. Di Gialleonardo V, Signore A, Scheerstra EA et al (2012) 11Chydroxytryptophan uptake and metabolism in endocrine and exocrine pancreas. J Nucl Med 53:1755-1763

25. Ekholm R, Ericson LE, Lundquist I (1971) Monoamines in the pancreatic islets of the mouse. Subcellular localization of 5hydroxytryptamine by electron microscopic autoradiography. Diabetologia 7:339-348

26. Selvaraju RK, Velikyan I, Johansson L et al (2013) In vivo imaging of the glucagonlike peptide 1 receptor in the pancreas with 68Galabeled DO3A-exendin-4. J Nucl Med 54:1458-1463

27. Singhal T, Ding YS, Weinzimmer D et al (2011) Pancreatic beta cell mass PET imaging and quantification with [11C]DTBZ and [18F]FP-(+)-DTBZ in rodent models of diabetes. Mol Imaging Biol 13:973-984

28. Eriksson O, Jahan M, Johnstrom $P$ et al (2010) In vivo and in vitro characterization of $[18 \mathrm{~F}]-\mathrm{FE}-(+)-\mathrm{DTBZ}$ as a tracer for beta-cell mass. Nucl Med Biol 37:357-363

29. Goland R, Freeby M, Parsey R et al (2009) 11C-dihydrotetrabenazine PET of the pancreas in subjects with long-standing type 1 diabetes and in healthy controls. J Nucl Med 50:382-389

30. Normandin MD, Petersen KF, Ding YS et al (2012) In vivo imaging of endogenous pancreatic beta-cell mass in healthy and type 1 diabetic subjects using $18 \mathrm{~F}$-fluoropropyl-dihydrotetrabenazine and PET. J Nucl Med 53:908-916

31. Freeby MJ, Kringas P, Goland RS et al (2015) Cross-sectional and test-retest characterization of PET with [(18)F]FP-(+)-DTBZ for beta cell mass estimates in diabetes. Mol Imaging Biol 18:292-301

32. Coppieters KT, Dotta F, Amirian N et al (2012) Demonstration of islet-autoreactive CD8 T cells in insulitic lesions from recent onset and long-term type 1 diabetes patients. J Exp Med 209:51-60

33. Keenan HA, Sun JK, Levine J et al (2010) Residual insulin production and pancreatic $\beta$-cell turnover after 50 years of diabetes: Joslin Medalist Study. Diabetes 59:2846-2853

34. Williams AJ, Thrower SL, Sequeiros IM et al (2012) Pancreatic volume is reduced in adult patients with recently diagnosed type 1 diabetes. J Clin Endocrinol Metab 97:E2109-E2113

35. Henderson JR, Daniel PM, Fraser PA (1981) The pancreas as a single organ: the influence of the endocrine upon the exocrine part of the gland. Gut 22:158-167
36. Mezza T, Kulkarni RN (2014) The regulation of pre- and postmaturational plasticity of mammalian islet cell mass. Diabetologia 57:1291-1303

37. Fagerholm V, Mikkola KK, Ishizu T et al (2010) Assessment of islet specificity of dihydrotetrabenazine radiotracer binding in rat pancreas and human pancreas. J Nucl Med 51:1439-1446

38. Harris PE, Farwell MD, Ichise M (2013) PET quantification of pancreatic VMAT 2 binding using $(+)$ and $(-)$ enantiomers of [(18)F]FP-DTBZ in baboons. Nucl Med Biol 40:60-64

39. Tsao HH, Skovronsky DM, Lin KJ, Yen TC, Wey SP, Kung MP (2011) Sigma receptor binding of tetrabenazine series tracers targeting VMAT2 in rat pancreas. Nucl Med Biol 38:1029-1034

40. Schafer MK, Hartwig NR, Kalmbach N et al (2013) Speciesspecific vesicular monoamine transporter 2 (VMAT2) expression in mammalian pancreatic beta cells: implications for optimising radioligand-based human beta cell mass (BCM) imaging in animal models. Diabetologia 56:1047-1056

41. Gianani R, Campbell-Thompson M, Sarkar SA et al (2010) Dimorphic histopathology of long-standing childhood-onset diabetes. Diabetologia 53:690-698

42. Butler AE, Janson J, Bonner-Weir S, Ritzel R, Rizza RA, Butler PC (2003) Beta-cell deficit and increased beta-cell apoptosis in humans with type 2 diabetes. Diabetes 52:102-110

43. Cnop M, Hughes SJ, Igoillo-Esteve M et al (2010) The long lifespan and low turnover of human islet beta cells estimated by mathematical modelling of lipofuscin accumulation. Diabetologia 53:321-330

44. Meier JJ, Butler AE, Saisho Y et al (2008) Beta-cell replication is the primary mechanism subserving the postnatal expansion of betacell mass in humans. Diabetes 57:1584-1594

45. Leeser DB, Bingaman AW, Poliakova L et al (2004) Pulsatile pump perfusion of pancreata before human islet cell isolation. Transplant Proc 36:1050-1051

46. Henquin JC, Rahier J (2011) Pancreatic alpha cell mass in European subjects with type 2 diabetes. Diabetologia 54:1720-1725

47. Kou K, Saisho Y, Sato S, Yamada T, Itoh H (2014) Islet number rather than islet size is a major determinant of beta- and alpha-cell mass in humans. J Clin Endocrinol Metab 99:1733-1740

48. Maffi P, Balzano G, Ponzoni M et al (2013) Autologous pancreatic islet transplantation in human bone marrow. Diabetes 62:3523-3531

49. Braun M, Wendt A, Karanauskaite J et al (2007) Corelease and differential exit via the fusion pore of GABA, serotonin, and ATP from LDCV in rat pancreatic beta cells. J Gen Physiol 129:221-231

50. Mannucci E, Tesi F, Bardini G et al (2004) Effects of metformin on glucagon-like peptide-1 levels in obese patients with and without type 2 diabetes. Diabetes Nutr Metab 17:336-342

51. Brom M, Oyen WJ, Joosten L, Gotthardt M, Boerman OC (2010) $68 \mathrm{Ga}$-labelled exendin-3, a new agent for the detection of insulinomas with PET. Eur J Nucl Med Mol Imaging 37:1345-1355

52. Selvaraju RK, Velikyan I, Asplund V et al (2014) Pre-clinical evaluation of [(68)Ga]Ga-DO3A-VS-Cys(40)-Exendin-4 for imaging of insulinoma. Nucl Med Biol 41:471-476

53. Korner M, Stockli M, Waser B, Reubi JC (2007) GLP-1 receptor expression in human tumors and human normal tissues: potential for in vivo targeting. J Nucl Med 48:736-743

54. Kung MP, Hou C, Lieberman BP et al (2008) In vivo imaging of beta-cell mass in rats using 18F-FP-(+)-DTBZ: a potential PET ligand for studying diabetes mellitus. J Nucl Med 49:1171-1176

55. Joosten L, Brom M, Bos D et al (2015) Non-invasive determination of the beta bell mass with ${ }^{111}$ In-exendin- 3 in a rat model of spontaneous type 1 diabetes. Diabetologia 58(Suppl 1):S101

56. Mathijs I, Xavier C, Peleman C et al (2015) A standardized method for in vivo mouse pancreas imaging and semiquantitative beta cell mass measurement by dual isotope SPECT. Mol Imaging Biol 17:58-66

57. Souza F, Simpson N, Raffo A et al (2006) Longitudinal noninvasive PET-based beta cell mass estimates in a spontaneous diabetes rat model. J Clin Invest 116:1506-1513 